\title{
Article \\ The Application of Fuzzy Theory in the Evaluation of Visual Images of Smartphone Rear Cameras
}

\author{
Chien-Hsiung Chen $+[$ and Zhongzhen Lin $*,+(\mathbb{C}$ \\ Department of Design, National Taiwan University of Science and Technology, No.43, Keelung Rd., Sec.4, \\ Da'an Dist., Taipei City 106335, Taiwan; cchen@mail.ntust.edu.tw \\ * Correspondence: d10710802@gapps.ntust.edu.tw; Tel.: +886-0903418880 \\ + These authors contributed equally to this work.
}

Citation: Chen, C.-H.; Lin, Z. The Application of Fuzzy Theory in the Evaluation of Visual Images of Smartphone Rear Cameras. Appl. Sci. 2021, 11, 3555. https://doi.org/ 10.3390/app11083555

Academic Editor: Enrico Vezzetti

Received: 12 March 2021

Accepted: 12 April 2021

Published: 15 April 2021

Publisher's Note: MDPI stays neutral with regard to jurisdictional claims in published maps and institutional affiliations.

Copyright: (c) 2020 by the authors. Licensee MDPI, Basel, Switzerland. This article is an open access article distributed under the terms and conditions of the Creative Commons Attribution (CC BY) license (https:// creativecommons.org/licenses/by/ $4.0 /)$.

\begin{abstract}
In the present era, technology is developing rapidly. Smartphones play a significant part in people's lives. However, the research on smartphones mainly focuses on the area of technological realization. The purposes of this study were to examine the relationship between the various rear cameras in smartphones and consumer perceptions, and to understand consumers' purchasing intentions and preferences. Through the methods of multidimensional scaling (MDS), factor analysis and triangular fuzzy numbers, the visual images of the smartphone rear cameras were analyzed and discussed. The results indicate that the visual images taken by different shapes of rear camera are quite distinct in the categories of innovative and fashionable, and simple and pure, but less distinct in the categories of harmonious and ordered, premium and technical, and superior and valuable. Through a comprehensive comparison, four groups whose images were similar were created. The outcome effectively reflects the potential consumer demands for smartphone rear camera patterns, providing insights for design practices in the smartphone industry.
\end{abstract}

Keywords: smartphone styling; multidimensional scaling; fuzzy logic; kansei engineering

\section{Introduction}

The use of smartphones is currently almost ubiquitous. According to the applications of smartphones in our daily lives, their functions have been divided into the following categories: productivity-emails; information searching-news website browsing; social interacting-social media; leisure and entertainment-games; and transactions—shopping history checking, etc. [1]. In a Pew Research study [2], 46 percent of smartphone users expressed that they could not live without a smartphone. Statistics indicate that the average smartphone owning ratio across the globe is 43 percent, and in the United States, it is 72 percent [3]. It is also estimated that over 5 billion people in the world possess mobile devices, more than half of which are smartphones [4]. With the evolution of fifth generation (5G) networks, smartphones are able to assist users and realize more potential in the Internet of Things (IOT), and in education, entertainment and mobile payments [5-7].

Through one experiment, it was found that price, brand preference, social impact and features affect consumer decision-making regarding smartphone purchasing, yet online surfing and demands on Wireless Fidelity (Wi-Fi) facilities result in users caring less about the price of smartphones [8]. However, with the evolution of technologiesvarious technical challenges have disappeared-smart devices have transformed rapidly, and function is no longer the dominant aspect in terms of consumer decision-making. The research of Jain and Singh [9] has also indicated that it is the psychographic factors that impact consumer buying willingness the most. The brands in the market are varied, and the options available to users are increasingly plentiful. Besides users' demands regarding functions, the aesthetic perceptions and psychographic impacts exerted by outside shaping and images are also matters of great importance. 
There exist a great many brands and kinds of smartphones. In Taiwan alone, there are a dozen brands on the market, all with certain differences in the form of the rear camera. Designs of different types may stimulate different consumer feelings, which further affect their preferences for forms [10]. In the design and development of new products, which are based on designers' past experience and aesthetic feelings, there might exist a gap between consumer and designer feelings. Users may have a different product image perception from that of designers, which would directly influence their degree of fondness for products. Therefore, an objective scheme for analysis and research into links between different kinds of rear cameras and various human visual and psychological factors, probing into users evaluations of various rear camera visual images, is conducive to narrowing perception gap between designers and users regarding the forms rear camera, while on the other hand improving smartphone design value, and providing assistance to phone makers, designers and users.

Therefore, designers should aim to satisfy users' potential psychological demands, and complement R\&D engineering work, so as to render a better smartphone user experience. The existing smartphones, size proportion, colors, rear case materials and rear cameras are all factors which collectively influence users' preferences for phone appearance. Most of the products are now taking the form of full display screens, creating a uniform look and style in the front. Consequently, the emphasis of design falls to the rear camera, which is regarded as an important element of smartphone's appearance and form.

From the above, it is clear that smartphones will be increasingly used and developed with amplitude in the future. A product's appearance is one of the most important factors influencing users' purchasing decisions, and different forms of products may bring different perceived values [11]. Emotion is an essential factor influencing customers' buying behavior [10]. Many researchers have attempted to apply statistical techniques to determine how product design features affect consumers' emotions, including regression analysis, fuzzy rule-based approaches and genetic algorithms [12-15]. Using these research methods, companies can design products that meet the consumers' emotional needs and indirectly influence their willingness to purchase products. However, most of the existing studies on the connection between smartphones and consumers' emotions focus on the overall appearance of smartphones and application interfaces [16-18]; there is less research on the design of smartphones' rear cameras. The results of this study are more rigorous, as representative samples were selected through a scientific sample selection method (i.e., multidimensional scaling (MDS)) and the samples were re-imaged in 2D to avoid interference from other factors, such as color.

The goals of this study were to analyze and explore consumers' visual and psychological perceptions of various forms of smartphone rear cameras, and to understand consumers' purchasing intentions and preferences, through objective methods such as Kansei engineering and fuzzy theory. We hope that the findings of this study will serve as a good reference for relevant practitioners, designers and consumers.

\section{Materials and Methods}

\subsection{Research Structure and Process}

As a consumer-oriented technique for new product design development, Kansei engineering can translate participants' feelings into design elements [19]. The purposes of this paper are to: (1) Help designers identify adjectives that highlight sustainability and innovation of smartphone rear cameras in new product design in order to incorporate emotional information into their design considerations. (2) To determine the perceived value of sustainability in smartphone rear camera design. (3) Integrate users' emotional perceptions to discuss purchasing desire and preferences for smartphone rear cameras. The smartphones on the Taiwanese market were taken as the subject of this research study. Opinions on visual images of various smartphone rear cameras were investigated. The research framework is illustrated in Figure 1. 


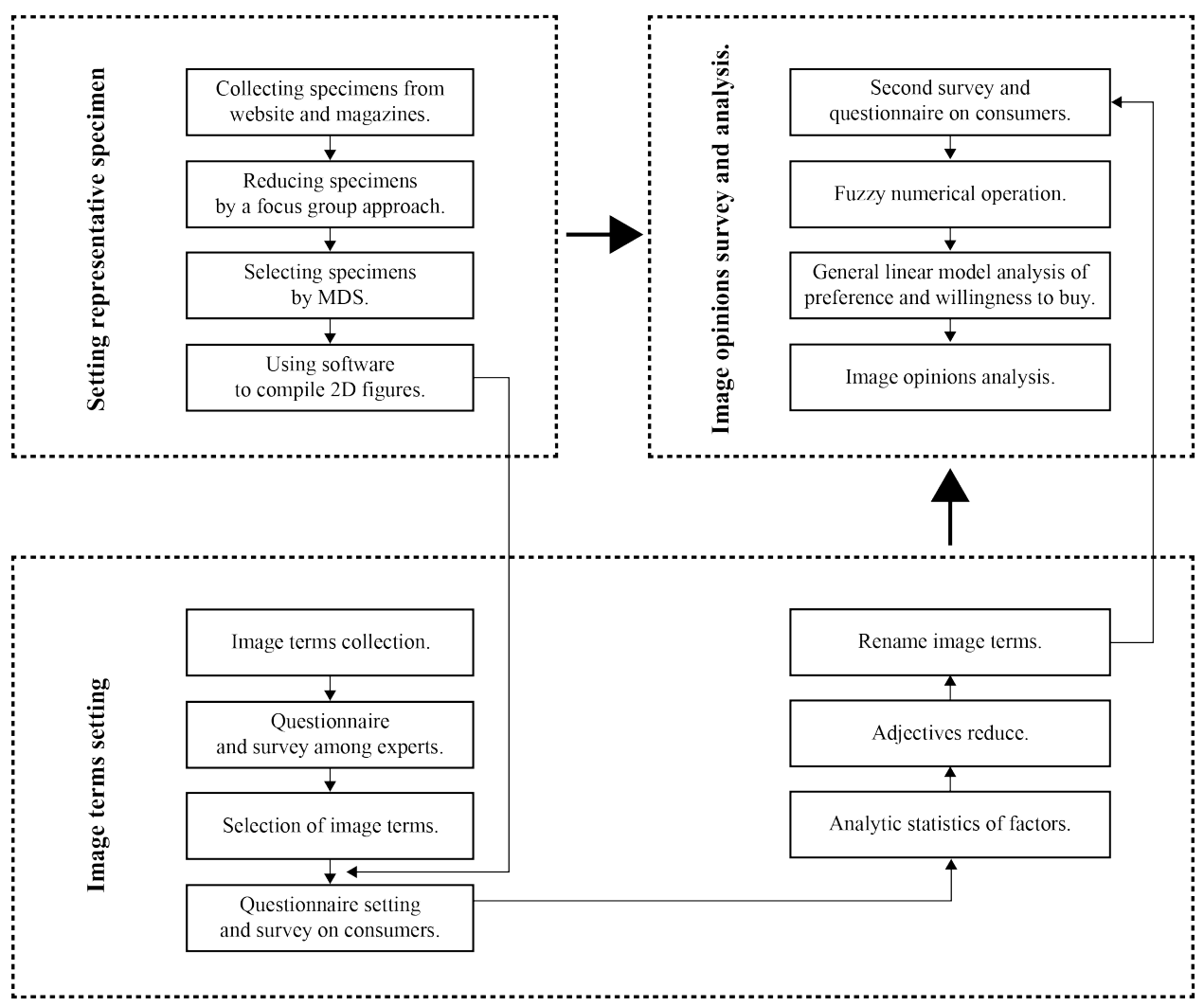

Figure 1. The research framework of this study.

\subsection{Selecting Representative Samples}

Multidimensional scaling (MDS) is a multi-variable analysis technique that reduces dimensions. Contrary to factor analysis, it adopts a distance matrix among spots as the input source, finding a space with fewer dimensions, and also a configuration of spots in that space (each spot stands for a consideration), enabling the configuration within which the distance between points is consistent with the input resource [20-23]. When choosing the optimum number of dimensions, it might refer to the minimum stress index in each dimension quantity scenario. The range of the value of the stress index is from 0 to 1 . A lower the stress index reflects a more appropriate dimension. With respect to Kruskal's interpretation, the matching degree under different stress indices is as in Table 1.

Table 1. Kruskal stress index interpretation.

\begin{tabular}{cc}
\hline Stress & Matching Degree \\
\hline 0.200 & Poor \\
0.100 & Fair \\
0.050 & Good \\
0.025 & Excellent \\
0.000 & Perfect \\
\hline
\end{tabular}

Materials in this research were taken from official smartphone websites and smartphone magazines. During the process, a total of 256 images of the rear elevation of smartphones which were clear and devoid of interference from the background were collected as samples. As there was a large number of samples, the focus group approach was applied to reduce the number, leaving 99 smartphone samples. The Adobe Photoshop software was used for coding the remaining samples; the gray scale process was performed and trademarks were removed, eliminating effects resulting from colors and brands. Afterwards, 12 experts were invited to take part in the testing (including 3 product design practitioners 
with $5+$ years of experience, 5 doctoral candidates and 4 lecturers in the design department). Based on their subjective feelings, the morphological characteristics of the rear cameras from the samples were grouped by similarity (the morphological characteristics included lens, flashlight, sensors and contour of the external camera, Figure 2). A total of 7-15 groups were created, based on which the similarity matrix was formed, and it was then converted into a dissimilarity matrix for MDS analysis. Lastly, the MDS results were taken as sorted variables, using cluster analysis for sample clustering, providing the final and most significant samples.

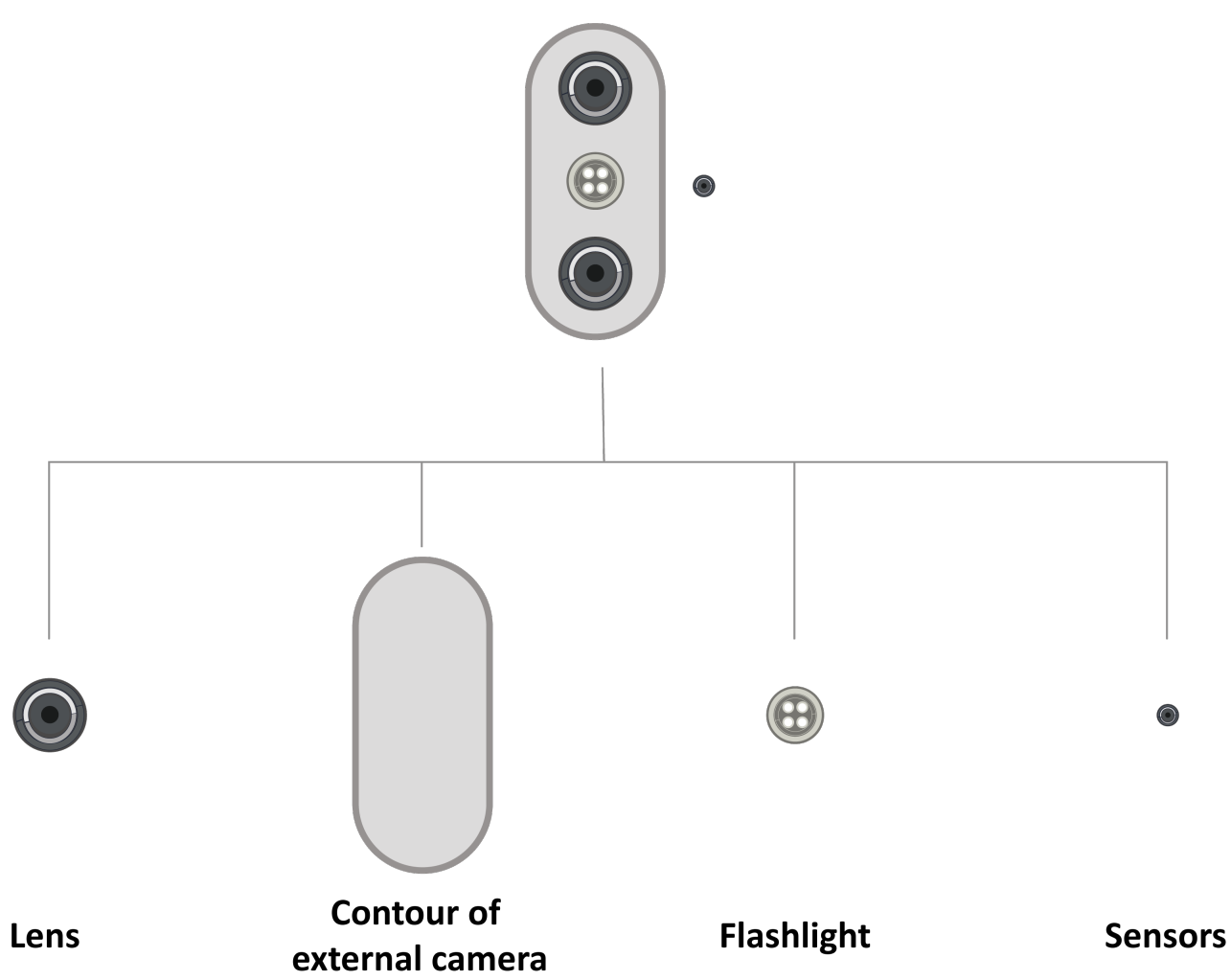

Figure 2. The formation of smartphone rear cameras.

\subsection{Extraction and Factor Analysis of Images Adjectives}

The adjectives relevant to the visual images of the smartphone rear cameras were sourced from each smartphone website and news website in Taiwan (news coverage of smartphone releases). After subjective sorting, 150 adjectives were picked for a further questionnaire to be administered to experts. Using the questionnaire method, the adjectives were sorted. A total of 17 experts were invited to take part in the experiment, including 2 secondary school Chinese language teachers, 10 postgraduates and 5 doctoral candidates majoring in design. The participants were asked to select, from the 150 images adjectives, 40-50 that best matched the visual images of the smartphone rear cameras. Lastly, the 40 most recognized adjectives were selected for further analysis according to mean selected times.

Factor analysis is generally used for the simplification of complex data [24]. Its main goal is to use a smaller number of dimensions to indicate the former data structure whilst reserving most of the information contained in the former structure [21]. Brown [25] defined factor analysis as one statistical method used for a determined number of factors in demand, and for explaining correlations in one set of variates. One factor is the equivalent of multi-correlated variates combined; it is therefore capable of measuring homogenous features. In short, factor analysis was adopted in this study to limit the number of images adjectives. In this phase, the 40 image adjectives were acquired, and consumer surveys were filled out using a Likert 5-point scale to obtain vocabulary differences. The degree scale 
consisted of "non-matching to a great extent", "non-matching", "normal", "matching" and "matching to a great extent." The questionnaires were collected from 134 participants (i.e., 61 males and 73 females). We implemented factor analysis for the acquired results, eliciting corresponding factor elements in image adjectives. Lastly, the factors were renamed according to the features of the image adjectives in the factor elements.

\subsection{Visual Image Opinions in Fuzzy Operation}

Fuzzy theory is a scientific approach for the research and treatment of obscure phenomena, and was first put forward by Zadeh in 1965 [26]. Zadeh held that humans' ideas, deductions and awareness of matters are substantially ambiguous in themselves. It is therefore necessary to apply fuzzy and logical concepts to describe priority degrees of matters. Through the membership function, it is possible to quantize subjects' inner feelings, converting feelings into numerical values between 0 and 1 , where the value denotes the potential influential factors and their respective impacts [26-28].

Fuzzy theory, in the application of meaning measuring, is an optimum approach for research. Nowadays, there are numerous design studies that have adopted fuzzy theory $[13,29,30]$. These studies usually adopt fuzzy numbers, of which the regular types are triangular fuzzy number, trapezoidal fuzzy number and normal fuzzy number, of which the triangular fuzzy number is the most common. What is special about the triangular fuzzy number is its affiliated function. The distribution of probabilities is in the form of a triangle [31]. Presuming one triangular fuzzy number int function $\mu_{i}(x)$, it is $t=\left(t_{1}, t_{2}, t_{3}\right)$, when $t_{1}, t_{2}$, and $t_{3}$ is a real number and $t_{1} \leq t_{2} \leq t_{3}$. This affiliated function is shown in Figure 3 [32].

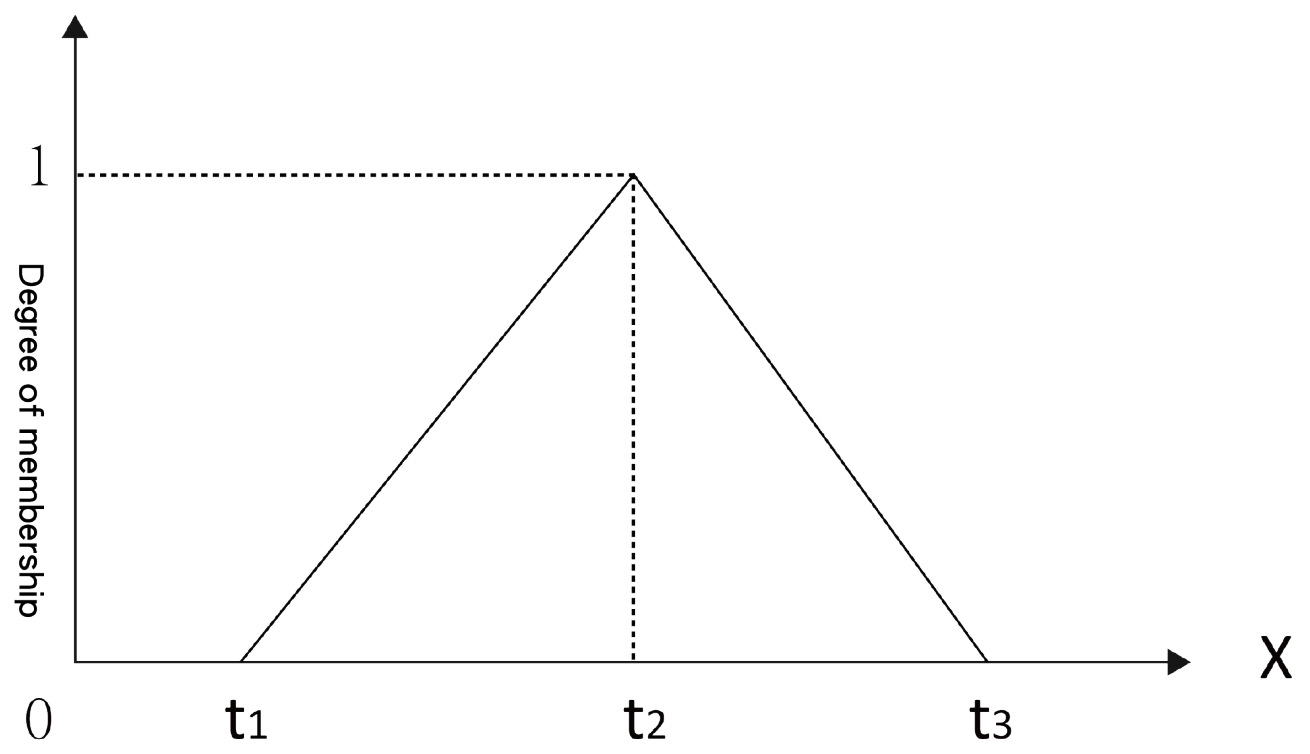

Figure 3. Membership function of a triangular fuzzy number.

This research study takes fuzzy meanings of seven grades as the ranking approach (see Table 2). Users were asked to rank the representative samples. The fuzzy ranking results were achieved by the 7-grade triangular affiliating function, making fuzzy meanings triangular fuzzy numbers after quantization. The triangular affiliating function is shown in Figure 4. 
Table 2. Linguistic variables for the importance and the ratings.

\begin{tabular}{cc}
\hline Linguistic Variables & Triangular Fuzzy Numbers \\
\hline Very Low (VL) & $(0,0,1)$ \\
Low (L) & $(0,1,3)$ \\
Medium Low (ML) & $(1,3,5)$ \\
Medium (M) & $(3,5,7)$ \\
Medium high (MH) & $(5,7,9)$ \\
High (H) & $(7,9,10)$ \\
Very High (VH) & $(9,10,10)$ \\
\hline
\end{tabular}

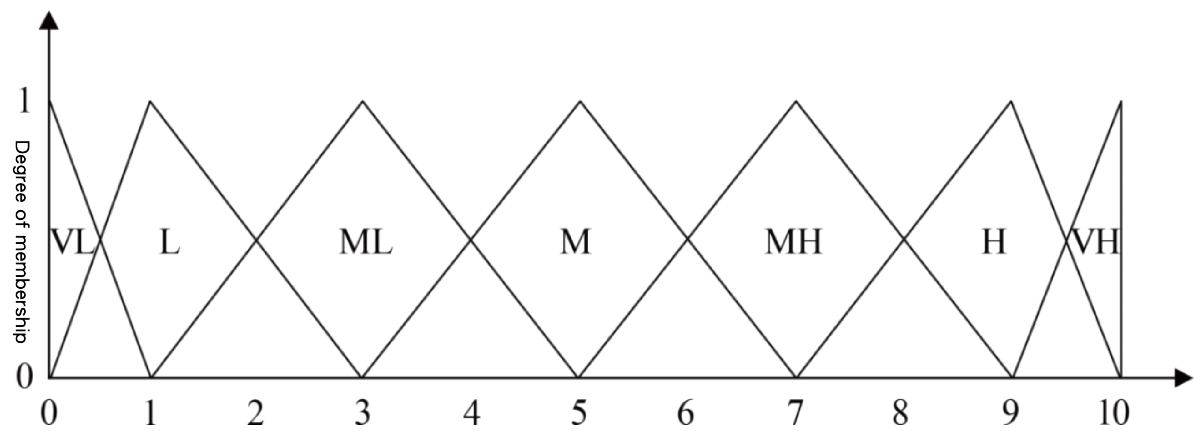

Figure 4. Membership function of a triangular fuzzy number.

For further analysis and comparison, defuzzification triangular fuzzy numbers in the affiliating function result in crisp values. The maximizing set and minimizing set method, put forward by Chen in 1985 [33], is the most common method for defuzzification and was adopted in this research. The principle is to make use of weights of two triangular fuzzy numbers to restore them to total utility values.

The questionnaire adopted in this research study was designed based on the fuzzy meaning principle. The questionnaire was administered with a 7-point Likert scale with 11 samples paired with five groups of factors; e.g., how would you rate sample S14 regarding being innovative and fashionable? How would you rate sample S14 regarding being harmonious and ordered? How would you rate sample S14 regarding being premium and technical? How would you rate sample S14 regarding being superior and valuable? How would you rate sample S14 regarding being simple and pure? This helped to identify the consumers' opinions on 11 rear camera samples. After defuzzification of the outcome, the total utility value of each form of visual image was obtained, diagrams and charts were drawn up and further analysis was performed on the 11 samples. The outcomes can provide insights for phone makers, designers and users.

\section{Results and Discussions}

\subsection{Selection Results of the Representative Samples}

The research, by means of MDS analysis, reached the best outcome with six dimensions (Stress $=0.03452$, RSQ $=0.98297)$, as shown in Table 3 .

Table 3. The stress and RSQ values of different dimensions of multidimensional scaling (MDS) analysis.

\begin{tabular}{ccc}
\hline Dimensions & Stress & RSQ \\
\hline 2 & 0.13782 & 0.90352 \\
3 & 0.06962 & 0.96207 \\
4 & 0.04902 & 0.97458 \\
5 & 0.04141 & 0.97865 \\
6 & 0.03452 & 0.98297 \\
\hline
\end{tabular}


The result of MDS was taken as a sorted variable, and by means of cluster analysis, the samples were divided into 11 categories, and the distance of each sample to the category center was also obtained (see Table 4). The one with the least distance to the center is the representative sample of its category. Besides, to reduce brand perception, which might seem rigid, or the influence of the phone's form, the software Adobe Illustrator was applied to convert these 11 representative samples into uniformly shaped 2D images (see Figure 5). The final converted 11 representative samples are shown in Figure 6.

Table 4. The results of cluster analysis.

\begin{tabular}{cccccc}
\hline Sample & Category & Distance & Sample & Category & Distance \\
\hline S33 & 1 & 0.969 & S49 & 7 & 0.58004 \\
S27 & 2 & 0.55683 & S50 & 8 & 0.85775 \\
S99 & 3 & 0.67183 & S14 & 9 & 0.93969 \\
S47 & 4 & 0.33529 & S58 & 10 & 0.54329 \\
S39 & 5 & 0.7289 & S74 & 11 & 0.2692 \\
S95 & 6 & 1.08983 & & & \\
\hline
\end{tabular}

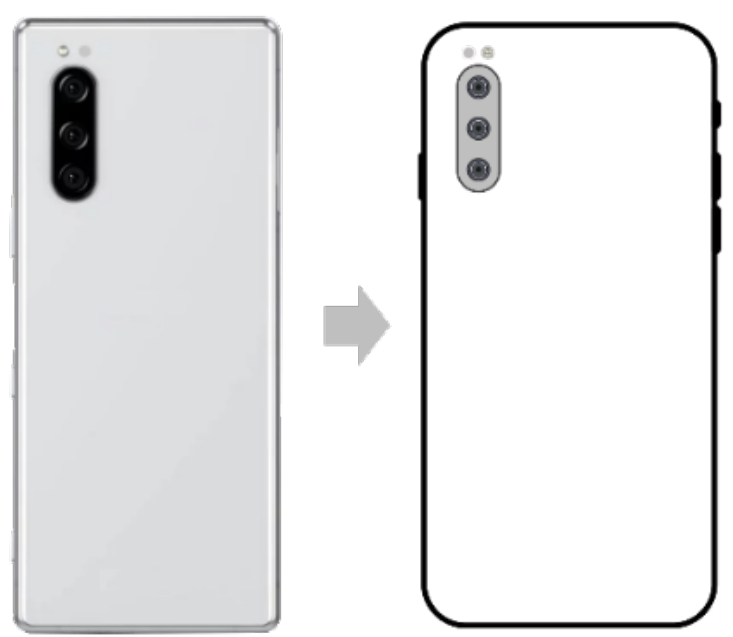

Figure 5. Representative samples converted into 2D images.

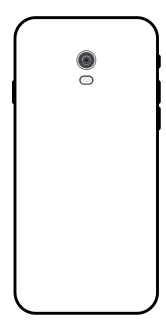

S14

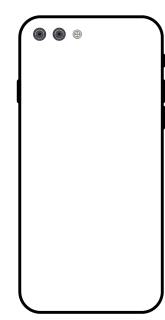

S50

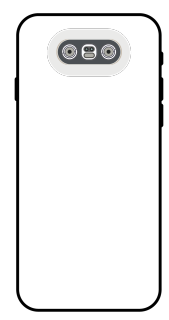

S27

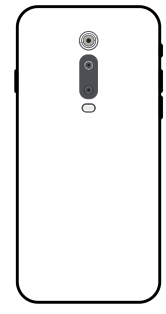

S33

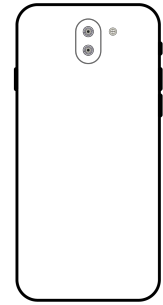

S39

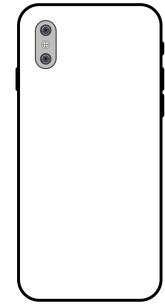

S47

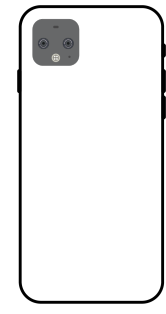

S49

Figure 6. Eleven representative samples.

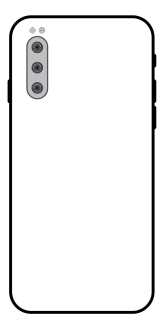

S74

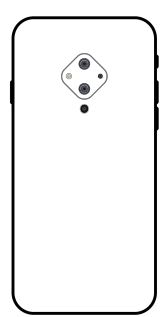

S95

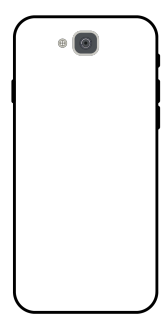

S99 


\subsection{Results of the Images Adjective Extraction and Factor Analysis}

Using the questionnaire method with expert participants, the image adjectives were sorted. A total of 17 experts were invited to take part in the experiment, including two secondary school Chinese language teachers, 10 postgraduates and 5 doctoral candidates majoring in design. Those participants were asked to select, from 150 adjectives, and with reference to the $2 \mathrm{D}$ diagrams of the representative samples (selected via the multi-scaling method), 40-50 adjectives that matched best with the visual images of the rear cameras of the smartphones. Lastly, based on mean selected times, the 40 most recognized terms were selected for further analysis (see Table 5).

Table 5. The 40 adjectives that were most recognized.

\begin{tabular}{ccccc}
\hline Scientific & Quality & Modern & Precise & Concise \\
Fascinating & Practical & Superior & Premium & Valuable \\
Advanced & Mechanical & Smart & Dense & Ordered \\
Durable & Future & Technical & Simple & Quality \\
Unique & Detailed & Fashionable & Rigid & Spotlit \\
Sequential & Harmonious & Convenient & Exquisite & Solid \\
Groundbreaking & Innovative & Balanced & Original & Uniform \\
Creative & Newfangled & Rational & Individual & Classic \\
\hline
\end{tabular}

The 40 most recognized adjectives were combined with the 11 representative samples for the images questionnaire. The results of the questionnaire were input into SPSS (a statistical software package) for analysis. Then through $\mathrm{T}$ test, 34 distinctive adjectives were sorted for the first factor analysis. After component analysis, 30 factors that contained load capacity values greater than 0.6 were chosen for the second factor analysis. The outcome is shown in Table 6.

Table 6. Thirty adjective factors with absolute load capacity values greater than 0.6.

\begin{tabular}{cccccc}
\hline Adjectives & Initial & Extraction & Adjectives & Initial & Extraction \\
\hline Concise & 1.000 & 0.703 & Simple & 1.000 & 0.731 \\
Fascinating & 1.000 & 0.745 & Quality & 1.000 & 0.755 \\
Superior & 1.000 & 0.743 & Unique & 1.000 & 0.692 \\
Premium & 1.000 & 0.678 & Fashionable & 1.000 & 0.659 \\
Valuable & 1.000 & 0.635 & Rigid & 1.000 & 0.634 \\
Mechanical & 1.000 & 0.622 & Spotlit & 1.000 & 0.728 \\
Ordered & 1.000 & 0.727 & Sequential & 1.000 & 0.720 \\
Durable & 1.000 & 0.752 & Harmonious & 1.000 & 0.744 \\
Future & 1.000 & 0.674 & Convenient & 1.000 & 0.723 \\
Technical & 1.000 & 0.666 & Solid & 1.000 & 0.724 \\
Groundbreaking & 1.000 & 0.750 & Innovative & 1.000 & 0.756 \\
Balanced & 1.000 & 0.628 & Original & 1.000 & 0.742 \\
Uniform & 1.000 & 0.742 & Creative & 1.000 & 0.725 \\
Newfangled & 1.000 & 0.742 & Rational & 1.000 & 0.686 \\
Individual & 1.000 & 0.726 & Classic & 1.000 & 0.706 \\
\hline
\end{tabular}

The KMO, after factor analysis, together with the Bartlett testing result, indicates that the $\mathrm{KMO}$ value was 0.931 , showing that the analysis material was appropriate. Bartlett's spherical testing value was $3191.715(\mathrm{df}=435, p=0.000)$, reaching significance, which represents that the relative matrix in the origin cluster contained common factors.

In contrast, in Table 7, the total variance denotes five factors with values greater than 1 , and shows a total variance quantity of 70.866 percent. From the transformed matrix, as shown in Table 8, five components of the last factor analysis are extremely distinct from each other, without coinciding with other factors. Therefore, the 30 adjectives and five components from this factor analysis were able to be further used. 
Table 7. Total variance explained.

\begin{tabular}{|c|c|c|c|c|c|c|c|c|c|}
\hline \multirow[b]{2}{*}{$\begin{array}{c}\text { Factor of } \\
\text { Component }\end{array}$} & \multicolumn{3}{|c|}{ Initial Eigenvalues } & \multicolumn{3}{|c|}{ Squares Loading Extraction } & \multicolumn{3}{|c|}{ Transformed Squares Loading } \\
\hline & Total & $\begin{array}{c}\text { Variance } \\
(\%)\end{array}$ & $\underset{(\%)}{\operatorname{Accumulative}}$ & Total & $\begin{array}{c}\text { Variance } \\
(\%)\end{array}$ & $\underset{(\%)}{\operatorname{Accumulative}}$ & Total & $\begin{array}{c}\text { Variance } \\
(\%)\end{array}$ & $\underset{(\%)}{\operatorname{Accumulative}}$ \\
\hline 1 & 14.827 & 49.422 & 49.422 & 14.827 & 49.422 & 49.422 & 6.785 & 22.617 & 22.617 \\
\hline 2 & 2.212 & 7.372 & 56.794 & 2.212 & 7.372 & 56.794 & 5.063 & 16.878 & 39.495 \\
\hline 3 & 1.705 & 5.684 & 62.478 & 1.705 & 5.684 & 62.478 & 3.369 & 11.229 & 50.724 \\
\hline 4 & 1.330 & 4.434 & 66.913 & 1.330 & 4.434 & 66.913 & 3.184 & 10.614 & 61.338 \\
\hline 5 & 1.186 & 3.953 & 70.866 & 1.186 & 3.953 & 70.866 & 2.858 & 9.528 & 70.866 \\
\hline
\end{tabular}

Table 8. Transformed component matrices.

\begin{tabular}{|c|c|c|c|c|c|}
\hline \multirow{2}{*}{ Adjectives } & \multicolumn{5}{|c|}{ Component } \\
\hline & 1 & 2 & 3 & 4 & 5 \\
\hline Individual & 0.770 & 0.247 & 0.162 & 0.208 & 0.051 \\
\hline Spotlit & 0.768 & 0.277 & 0.159 & 0.153 & 0.118 \\
\hline Groundbreaking & 0.767 & 0.031 & 0.311 & 0.155 & 0.201 \\
\hline Innovative & 0.760 & 0.218 & 0.336 & 0.114 & 0.061 \\
\hline Unique & 0.755 & 0.104 & 0.014 & 0.220 & 0.250 \\
\hline Original & 0.748 & 0.265 & 0.175 & 0.227 & 0.174 \\
\hline Newfangled & 0.728 & 0.384 & 0.182 & 0.162 & 0.074 \\
\hline Fashionable & 0.587 & 0.284 & 0.216 & 0.250 & 0.353 \\
\hline Creative & 0.575 & 0.541 & 0.193 & 0.183 & 0.177 \\
\hline Classic & 0.498 & 0.129 & 0.494 & 0.095 & 0.434 \\
\hline Rational & 0.110 & 0.766 & 0.294 & 0.004 & -0.040 \\
\hline Ordered & 0.013 & 0.749 & 0.042 & 0.383 & 0.135 \\
\hline Sequential & 0.301 & 0.725 & 0.210 & 0.114 & 0.217 \\
\hline Rigid & 0.295 & 0.700 & 0.173 & 0.160 & 0.030 \\
\hline Uniform & 0.331 & 0.652 & 0.147 & 0.005 & 0.431 \\
\hline Balanced & 0.410 & 0.564 & 0.202 & 0.177 & 0.264 \\
\hline Mechanical & 0.198 & 0.560 & 0.021 & 0.518 & -0.014 \\
\hline Harmonious & 0.312 & 0.551 & 0.247 & -0.026 & 0.531 \\
\hline Convenient & 0.237 & 0.337 & 0.686 & -0.006 & 0.287 \\
\hline Durable & 0.139 & 0.244 & 0.666 & 0.457 & 0.141 \\
\hline Solid & 0.363 & 0.364 & 0.656 & 0.151 & 0.084 \\
\hline Quality & 0.422 & 0.195 & 0.546 & 0.354 & 0.340 \\
\hline Technical & 0.379 & 0.155 & 0.502 & 0.454 & 0.199 \\
\hline Superior & 0.250 & 0.150 & 0.233 & 0.669 & 0.395 \\
\hline Future & 0.487 & 0.042 & 0.210 & 0.616 & 0.111 \\
\hline Valuable & 0.292 & 0.381 & 0.315 & 0.547 & -0.082 \\
\hline Fascinating & 0.489 & 0.164 & -0.174 & 0.545 & 0.389 \\
\hline Premium & 0.188 & 0.203 & 0.448 & 0.539 & 0.333 \\
\hline Concise & 0.221 & -0.033 & 0.147 & 0.255 & 0.753 \\
\hline Simple & 0.113 & 0.361 & 0.292 & 0.143 & 0.695 \\
\hline
\end{tabular}

In this research, it was necessary to acquire adjectives that are appropriate for evaluating the visual images of smartphone rear cameras. Therefore, using factor analysis, from 150 adjectives, 30 image adjective clusters were created, consisting of five factors. The outcome was the creation of five basic dimensions of images for further research: innovative and fashionable; harmonious and ordered; premium and technical; superior and valuable; and simple and pure (see Table 9).

Table 9. Factor renaming list.

\begin{tabular}{ccc}
\hline Factor & Factor Naming & Adjective Groups \\
\hline 1 & Innovative and Fashionable & $\begin{array}{c}\text { Individual; Spotlit; Groundbreaking; Innovative; Unique; } \\
\text { Original; Newfangled; Fashionable; Creative; Classic }\end{array}$ \\
\hline 2 & Harmonious and Ordered & $\begin{array}{c}\text { Rational; Ordered; Sequential; Rigid; Uniform; Balanced; } \\
\text { Mechanical; Harmonious }\end{array}$ \\
\hline 3 & Premium and Technical & Convenient; Durable; Solid; Quality; Technical \\
\hline 4 & Superior and Valuable & Superior; Future; Valuable; Fascinating; Premium \\
\hline 5 & Simple and Pure & Concise; Simple \\
\hline
\end{tabular}

\subsection{The Results of Fuzzy Operation}

Based on 11 representative samples (i.e., 2D images) from Figure 6, in combination with the five categories of renamed visual image adjectives in Table 9, a visual images 
evaluation questionnaire was devised in accordance with the 7-phase fuzzy meaning scale, as shown in Table 2. A total of 155 participants, 72 males and 83 females, were invited for the experiment by using the convenience sampling method. Their ages ranged from 18 to 40 years old. The questionnaire outcome, through the triangular affiliating function, quantified fuzzy meaning into triangular fuzzy numbers. After adding together and averaging, the mean values are shown in Table 10. Then, by the sequence of visual image evaluation samples, the fuzzy triangular diagram was drawn (see Figure 7).

Table 10. The sequence and means of the visual evaluations of the samples of the smartphone rear cameras.

\begin{tabular}{|c|c|c|c|c|}
\hline $\begin{array}{l}\text { Innovative and } \\
\text { Fashionable }\end{array}$ & $\begin{array}{l}\text { Harmonious and } \\
\text { Ordered }\end{array}$ & $\begin{array}{l}\text { Premium and } \\
\text { Technical }\end{array}$ & $\begin{array}{l}\text { Superior and } \\
\text { Valuable }\end{array}$ & Simple and Pure \\
\hline S95 (5.0 6.79 .0$)$ & S47 (4.5 6.4 8.1) & S74 (4.3 6.2 7.8) & S74 (4.5 6.3 7.9) & S47 (4.8 6.68 .2$)$ \\
\hline S74 (4.2 6.0 7.7) & S74 (4.4 6.3 7.9) & S33 (3.9 5.8 7.5) & S95 (4.0 5.8 7.4) & S39 (4.6 6.4 8.0) \\
\hline S33 (4.0 5.87 .5$)$ & S39 (4.1 5.9 7.6) & S95 (4.0 5.8 7.4) & S33 (3.6 5.5 7.3) & S14 (4.9 6.6 8.0) \\
\hline S47 (3.7 5.6 7.4) & S33 (3.9 5.8 7.5) & S47 (3.8 5.7 7.4) & S47 (3.6 5.4 7.2) & S99 (4.2 6.0 7.6) \\
\hline S50 (3.8 5.57 .2$)$ & S50 (3.8 5.6 7.3) & S50 (3.6 5.4 7.1) & S58 (3.6 5.4 7.2) & S50 (4.0 5.8 7.5) \\
\hline S58 (3.6 5.4 7.1) & S14 (3.9 5.6 7.2) & S58 (3.5 5.3 7.1) & S50 (3.2 5.0 6.8) & S74 (3.8 5.6 7.4) \\
\hline S27 (3.9 5.57 .0$)$ & S99 (3.6 5.4 7.2) & S39 (3.2 5.1 6.9) & S27 (3.5 5.2 6.8) & S33 (3.4 5.1 6.8) \\
\hline S49 (3.4 5.1 6.7) & S58 (3.7 5.5 7.2) & S27 (3.5 5.2 6.8) & S99 (2.8 4.6 6.3) & S58 (3.1 4.9 6.7) \\
\hline S14 (3.2 4.86 .4$)$ & S95 (3.7 5.5 7.2) & S99 (3.2 5.0 6.8) & S49 (2.9 4.6 6.3) & S95 (3.1 4.86 .6$)$ \\
\hline S99 (3.0 4.76 .4$)$ & S27 (3.0 4.76 .3$)$ & S14 (3.4 5.1 6.8) & S14 (2.9 4.5 6.2) & S27 (2.3 3.85 .5$)$ \\
\hline S39 (2.3 4.0 5.8) & S49 (2.5 4.0 5.7) & S49 (2.9 4.56 .2$)$ & S39 (2.5 4.2 6.0) & S49 (2.0 3.5 5.3) \\
\hline
\end{tabular}
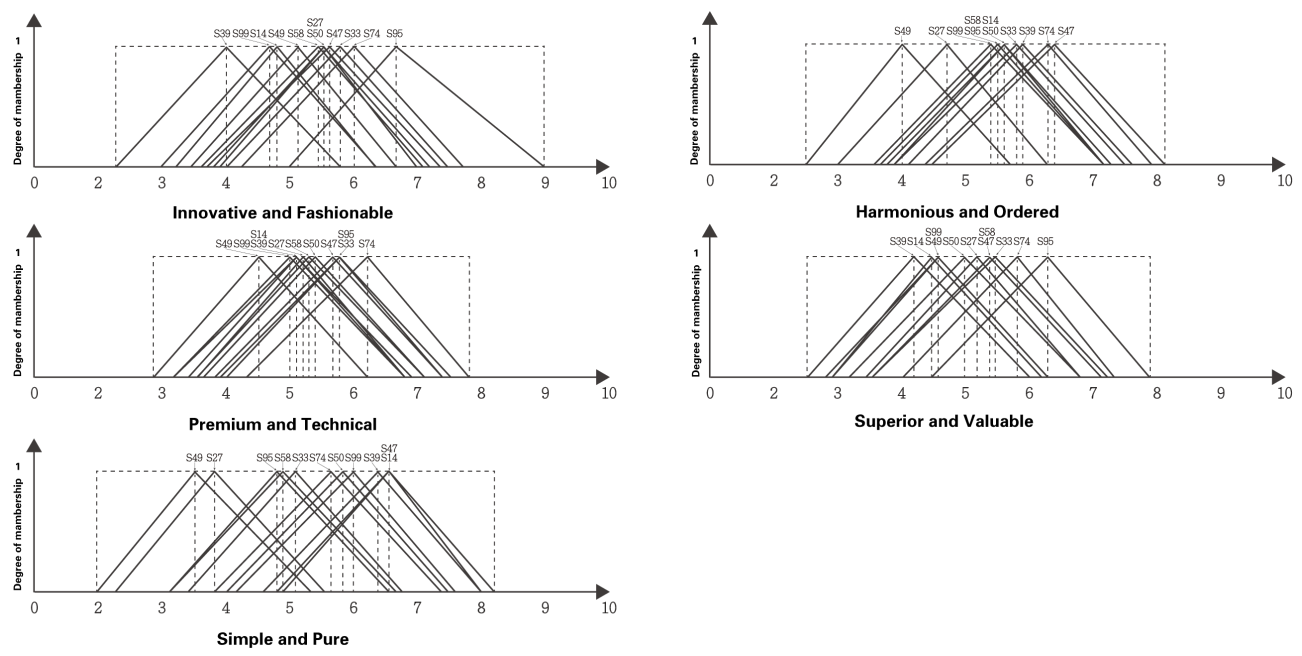

Figure 7. The triangular fuzzy numbers of the 11 representative samples in each visual evaluation.

The triangular fuzzy number in Table 10, after defuzzification with the absolute utility value formula, produced the absolute utility value of the 11 representative visual image evaluations (Table 11). The detailed calculation is as follows:

Presume $\mathrm{n}$ numbers of triangular fuzzy number in an affiliating function; define it as $\widetilde{\mathbf{t}_{\mathbf{i}}}=\left(\mathbf{t}_{1}, \mathbf{t}_{2}, \mathbf{t}_{3}\right), \mathbf{i}=1,2, \ldots, \mathbf{n}$; in this way, the minimum $\mu_{G}(x)$ and maximum $\mu_{M}(x)$ are respectively $G$ and $M$. The absolute utility value of $\mathbf{U}_{\mathbf{T}}\left(\widetilde{t}_{\mathbf{i}}\right)$ is as Equation 1 shows:

$$
\begin{aligned}
& \mathbf{U}_{\mathbf{T}}\left(\widetilde{\mathbf{T}}_{\mathbf{I}}\right)=\left[\frac{\left(\mathbf{T}_{\mathbf{I} 3}-\mathbf{X}_{\mathrm{MIN}}\right)}{\left(\left(\mathbf{X}_{\mathrm{MAX}}-\mathbf{X}_{\mathrm{MIN}}\right)+\left(\mathbf{T}_{\mathbf{I} 3}-\mathbf{T}_{\mathbf{I} 2}\right)\right)}+\mathbf{1}-\frac{\left(\mathbf{X}_{\mathrm{MIN}}-\mathbf{t}_{\mathbf{i} 1}\right)}{\left(\left(\mathbf{X}_{\mathrm{MAX}}-\mathbf{X}_{\mathrm{MIN}}\right)+\left(\mathbf{T}_{\mathbf{I} 2}-\mathbf{T}_{\mathbf{I} 1}\right)\right)}\right] / \mathbf{2}, \\
& \mathbf{i}=1,2, \ldots, \mathbf{n}
\end{aligned}
$$


Table 11. The total utility values of 11 samples of smartphone rear cameras.

\begin{tabular}{cccccc}
\hline Samples & $\begin{array}{c}\text { Innovative and } \\
\text { Fashionable }\end{array}$ & $\begin{array}{c}\text { Harmonious } \\
\text { and Ordered }\end{array}$ & $\begin{array}{c}\text { Premium and } \\
\text { Technical }\end{array}$ & $\begin{array}{c}\text { Superior and } \\
\text { Valuable }\end{array}$ & $\begin{array}{c}\text { Simple and } \\
\text { Pure }\end{array}$ \\
\hline S14 & 0.3976 & 0.5387 & 0.4621 & 0.4034 & 0.6859 \\
S27 & 0.4794 & 0.4146 & 0.4742 & 0.4973 & 0.3384 \\
S33 & 0.5154 & 0.5625 & 0.5617 & 0.5388 & 0.5000 \\
S39 & 0.3071 & 0.5790 & 0.4603 & 0.3628 & 0.4929 \\
S47 & 0.4919 & 0.6436 & 0.5468 & 0.5278 & 0.6849 \\
S49 & 0.4317 & 0.3248 & 0.3731 & 0.4155 & 0.3037 \\
S50 & 0.4821 & 0.5382 & 0.5048 & 0.4722 & 0.5856 \\
S58 & 0.5278 & 0.4750 & 0.4681 & 0.5246 & 0.4925 \\
S74 & 0.5391 & 0.6283 & 0.6196 & 0.6496 & 0.5625 \\
S95 & 0.6341 & 0.5246 & 0.5626 & 0.5792 & 0.4647 \\
S99 & 0.3869 & 0.5135 & 0.4478 & 0.4134 & 0.6090 \\
\hline
\end{tabular}

The above results state:

In Figure 7, it is shown that different smartphone rear cameras received different visual evaluations in the categories of "fashionable and technical" and "superior and valuable"; yet in the categories of "premium and technical" and "superior and valuable", the distinctions were limited.

As shown in Table 10 statistics, sample S14 received the highest grades in the evaluation for the category "simple and pure"; sample S47 received high grades in categories "harmonious and ordered" and "simple and pure"; sample S74 received great grades in each evaluation, achieving its best grades in "premium and technical" and "superior and valuable"; sample S95 received good grades except in "superior and valuable", and its highest grade appeared in the evaluation of "superior and valuable". The above results can also be summarized as follows:

From Figure 7, it can be seen that different smartphone rear cameras have apparently different visual qualities in the categories of "fashionable and technical," and "superior and valuable," while in the categories of "premium and technical" and "superior and valuable," the distinctions are limited.

As shown in Table 10, sample S14 received the highest grade in the evaluation for the category "simple and pure"; sample S47 received high grades in both the "harmonious and ordered" and "simple and pure" categories; sample S74 received great grades in each evaluation, achieving its best grades in "premium and technical" and "superior and valuable"; sample S95 received good grades except for "superior and valuable," and its highest grade appeared in the evaluation of "innovative and fashionable."

Images evaluation grades, after further processing with a radar map (see Figure 8) and a comprehensive comparison, led to the four clusters of the entire visual images evaluation: (a) similar images appeared in S14 and S99, and they both acquired high evaluation grades in "superior and valuable"; (b) for S27, S39 and S49, the linear radius was within the innermost ring, indicating that the visual images were close on the whole, and low grades were received for each images evaluation; (c) S33, S47, S74 and S95 possessed similar visual images on the whole, with relatively higher grades for each evaluation, and an even distribution; (d) S50 and S58 had similar linear radii devoid of extreme highs or extreme lows, denoting an interim level in each visual image evaluation. 


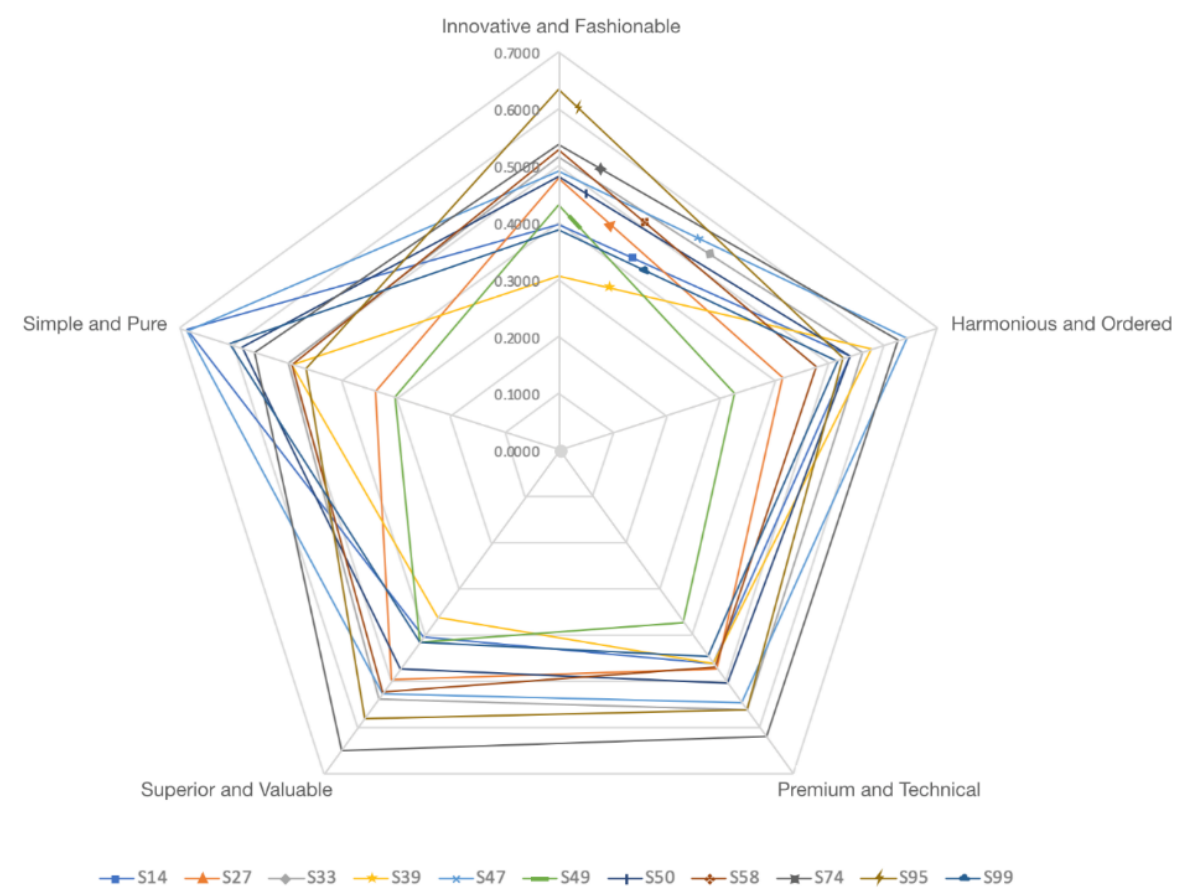

Figure 8. The radar map for visual image evaluation.

\subsection{The Results of the Effect of Willingness to Buy}

According to the results of the general linear model shown in Table 12, it was revealed that the purchasing intentions toward different smartphone rear cameras showed significant differences $\left(\mathrm{F}_{(10,1100)}=11.170, p=0.000\right)$. The results from the post hoc test (i.e., $\mathrm{LSD}$ ) results show specific differences between samples; i.e., participants were significantly more willing to purchase S14 than S27, S49 and S58; however, participants perceived S14 as significantly less worthy than S47. Participants' purchasing intentions for S27 were significantly lower than for S14, S33, S39, S47, S50, S58, S74, S95 and S99; participants' purchasing intentions for S33 were significantly higher than for S27 and S49; participants' purchasing intentions for S33 were significantly lower than for S39, S47, S50 and S74; participants' purchasing intentions for S39 were significantly higher than for S27, S33, S39, S47, S50 and S99; participants' purchasing intentions for S39 were significantly higher than for S27, S33, S49, S58 and S95; participants' purchasing intentions for S39 were significantly lower than those for S47; participants' purchasing intentions for S47 were significantly higher than those for S14, S27, S33, S39, S47, S50, S58, S74, S95 and S99; participants' purchasing intentions for S49 were significantly lower than those for S14, S33, S39, S47, S50, S58, S74, S95 and S99; participants' purchasing intentions for S50 were significantly higher than those for S27, S33, S49 and S58; participants' purchasing intentions for S50 were significantly lower than those for S47; participants' purchasing intentions for S58 were significantly higher than those for S27 and S49; participants' purchasing intentions for S58 were significantly lower than those for S14, S39, S47, S50, S74 and S99; participants' purchasing intentions for S74 were significantly lower than for S27, S33, S47, S49, S59 and S95; participants' purchasing intentions for S95 were significantly higher than for S27 and S49; participants' purchasing intentions for S95 were significantly lower than for S39, S47 and S74; participants' purchasing intentions for S99 were significantly higher than for S27, S49 and S58; participants' purchasing intentions for S99 were significantly higher than for S27, S49 and S58; participants' purchasing intentions for S99 were significantly lower than for S47.

Based on the mean results, participants expressed higher purchasing intentions for S39 $(\mathrm{M}=4.04, \mathrm{SD}=1.22)$ and $\mathrm{S} 47(\mathrm{M}=4.43, \mathrm{SD}=1.29)$, and higher purchasing intentions for $\mathrm{S} 14(\mathrm{M}=3.87, \mathrm{SD}=1.47), \mathrm{S} 27(\mathrm{M}=3.12, \mathrm{SD}=1.62), \mathrm{S} 33(\mathrm{M}=3.54, \mathrm{SD}=1.41), \mathrm{S} 49(\mathrm{M}=3.05$, $\mathrm{SD}=1.55), \mathrm{S} 50(\mathrm{M}=3.93, \mathrm{SD}=1.46), \mathrm{S} 58(\mathrm{M}=3.52, \mathrm{SD}=1.35), \mathrm{S} 74(\mathrm{M}=3.99, \mathrm{SD}=1.44)$, 
S95 ( $\mathrm{M}=3.60, \mathrm{SD}=1.56)$ and $\mathrm{S} 99(\mathrm{M}=3.80, \mathrm{SD}=1.29)$, for which they expressed the lowest purchasing intentions. However, participants perceived a significant difference between S39 and S47 (i.e., S39 < S47). Although participants expressed a willingness to purchase both S39 and S47, participants were significantly more willing to purchase S47 than S39.

Table 12. The results of the general linear model.

\begin{tabular}{|c|c|c|c|c|c|c|c|}
\hline Source & SS & $\mathrm{DF}$ & MS & $\mathbf{F}$ & $\mathbf{P}$ & $\eta 2$ & LSD \\
\hline $\begin{array}{l}\text { Rear cameras } \\
\text { (11 samples) }\end{array}$ & 182.419 & 10 & 18.242 & 11.170 & $0.000 * *$ & 0.092 & 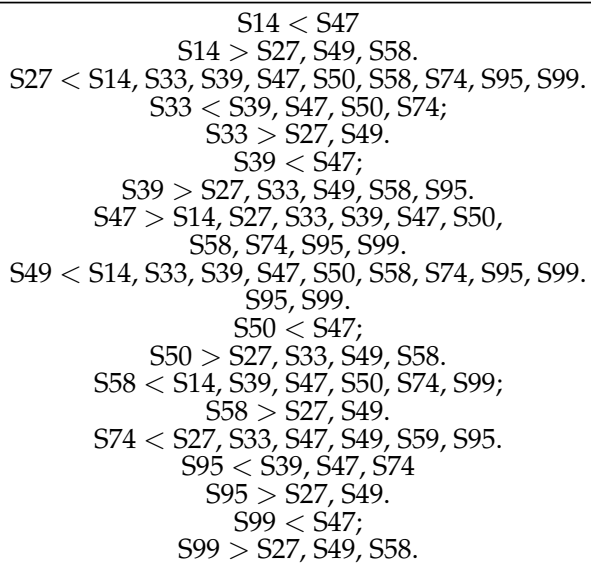 \\
\hline
\end{tabular}

** Significantly different at $\alpha=0.01$ level $(p<0.01)$.

Besides, combined with the fuzzy logic results (see Section 3.4), participants scored S39 and $\mathrm{S} 47$ higher on the harmonious and ordered dimension, 0.5790 and 0.6436 , respectively. However, S49 had a lower score for the harmonious and ordered dimension. This suggests that the harmonious and ordered dimension is likely to be an important factor influencing participants' purchasing intentions.

\subsection{The Results of the Effect of Preference}

According to the results of the general linear model shown in Table 13, the main effect of preference for different smartphone rear cameras showed significant differences $\left(\mathrm{F}_{(10,1100)}=10.80, p=0.000<0.01\right)$. The post hoc test (i.e., LSD) results showed specific differences between samples; i.e., participants' preference for S14 was significantly stronger than for S27, S49 and S58; participants' preference for S14 was significantly weaker than for S47; participants' preference for S27 was significantly weaker than for S14, S33, S39, S47, S50, S58, S74, S95 and S99; participants' preference for S33 was significantly stronger than for S27 and S49; participants' preference for S33 was significantly weaker than for S39, S47 and S74; participants' preference for S39 was significantly stronger than for S27, S49, S58, S95 and S99; participants' preference for S47 was significantly stronger than for S14, S27, S33, S49, S50, S58, S74, S95 and S99; participants had a significantly weaker preference for S49 than for S14, S33, S39, S47, S50, S58, S74, S95 and S99; participants had a significantly stronger preference for S50 than for S27, S49 and S58; participants had a significantly weaker preference for S50 than for S47; participants had a significantly stronger preference for S58 than for S27 and S49; participants had a significantly weaker preference for S58 than for S14, S39, S47, S50, S74, S95 and S99; participants had a significantly stronger preference for S74 than for S27, S33, S49 and S58; participants had a significantly weaker preference for S74 than for S47; participants had a significantly stronger preference for S95 than for S27 and S49; participants had significantly weaker preference was significantly weaker than for S39 and S47; participants' preference for S99 was significantly stronger than for S27, S49 and S58; participants' preference for S99 was significantly weaker than for S39 and S47.

Based on the mean results, participants expressed comparative preferences for S39 $(\mathrm{M}=4.25, \mathrm{SD}=1.20), \mathrm{S} 47(\mathrm{M}=4.47, \mathrm{SD}=1.27)$ and $\mathrm{S} 74(\mathrm{M}=4.11, \mathrm{SD}=1.37)$; and for $\mathrm{S} 14$ $(\mathrm{M}=3.94, \mathrm{SD}=1.54), \mathrm{S} 27(\mathrm{M}=3.24, \mathrm{SD}=1.57), \mathrm{S} 33(\mathrm{M}=3.68, \mathrm{SD}=1.38), \mathrm{S} 49(\mathrm{M}=3.20$, $\mathrm{SD}=1.54), \mathrm{S} 50(\mathrm{M}=3.99, \mathrm{SD}=1.51), \mathrm{S} 58(\mathrm{M}=3.59, \mathrm{SD}=1.27), \mathrm{S} 95(\mathrm{M}=3.78, \mathrm{SD}=1.55)$ 
and S99 $(\mathrm{M}=3.87, \mathrm{SD}=1.29)$ they indicated the opposite. However, participants perceived a significant difference between S47 and S74 (i.e., S47 > S74). Although participants expressed a preference for both S47 and S74, participants liked S47 significantly more than S74.

Table 13. The results of the general linear model.

\begin{tabular}{|c|c|c|c|c|c|c|c|}
\hline Source & SS & DF & MS & $\mathbf{F}$ & $\mathbf{P}$ & $\eta 2$ & LSD \\
\hline $\begin{array}{l}\text { Rear cameras } \\
\text { (11 samples) }\end{array}$ & 169.342 & 10 & 16.93 & 10.80 & $0.000^{* *}$ & 0.89 & $\begin{array}{c}\text { S14 < S47 } \\
\text { S14 > S27, S49, S58, } \\
\text { S27 < S14, S33, S39, S47, S50, S58, S74, S95 } \\
\text { S99, } \\
\text { S33 < S39, S47, S74, } \\
\text { S33 > S27, S49, } \\
\text { S39 }>\text { S27, S49, S58, S95, S99, } \\
\text { S47 > S14, S27, S33, S49, S50, S58, S74, S95 } \\
\text { S99 } \\
\text { S49< S14, S33, S39, S47, S50, S58, S74, S95 } \\
\text { S99, } \\
\text { S50 < S47, } \\
\text { S50 > S27, S49, S58, } \\
\text { S58 < S14, S39, S47, S50, S74, S95, S99, } \\
\text { S58 > S27, S49, } \\
\text { S74 < S47, } \\
\text { S74 }>\text { S27, S33, S49, S58, } \\
\text { S95 < S39, S47, } \\
\text { S95 > S27, S49, } \\
\text { S99 < S39, S47, } \\
\text { S99 }>\text { S27, S49, S58. }\end{array}$ \\
\hline
\end{tabular}

** Significantly different at $\alpha=0.01$ level $(p<0.01)$.

\section{Conclusions}

This research applied a consolidated approach of MDS, cluster analysis, questionnaires among experts, factor analysis and fuzzy theory to study the visual images of smartphone rear cameras. Due to the fact that the accuracy of the evaluation samples and image adjectives would have further affected the objectivity and accuracy of the research outcome, we first used MDS and cluster analysis to sort out the representative samples; then through an expert-questionnaire and factor analysis, the image adjectives were efficiently selected. Lastly, triangular fuzzy number operation in the area of fuzzy theory was used to further analyze the visual image evaluations of the smartphone rear cameras. The sample selection method in this study was a scientific technique. This study differed from previous studies in that the samples were converted to $2 \mathrm{D}$ images to avoid confounding factors, such as color and brand preference. The study also unpacked the composition of the smartphone rear camera (as shown in Figure 2) so that companies and designers can make better use of the findings of this study.

The outcomes show that different shapes of smartphone rear cameras present unique visuals. A total of 11 representative samples had distinct evaluation results in the dimensions of "innovative and fashionable" and "simple and pure," but narrow distinctions in the aspects of "harmonious and ordered," "premium and technical" and "superior and valuable." Some of the samples contained similarities on the whole; for instance, for S14 and S99, some evaluation results were similar. Therefore, alternatives to those two might be taken into account by phone makers and designers.

The results of this research can be applied in the development of new smartphones. For the direction of further research, combining phone size proportion and colors might be considered. The approaches that have been shown in this paper, devised for the acquisition of visual image evaluation values of smartphone rear camera forms, entailed the establishment of an auxiliary design system for smartphones. Matters worthy of consideration are that disparities exist in the lives of users from different countries, which might lead to varied sentimental demands and aesthetic preferences. The participants were all from Taiwan or Mainland China, so they had similar cultural backgrounds. It is also advised that further research may take cultural background as a variate. If the inclination 
towards visual images on the part of users is correctly handled, then smartphones that comply to consumer thoughts and demands can be devised.

Author Contributions: Conceptualization, Z.L. and C.-H.C.; methodology, Z.L. and C.-H.C.; investigation, Z.L.; formal analysis, Z.L.; writing—original draft preparation, Z.L.; writing—review and editing, C.-H.C.; All authors have read and agreed to the published version of the manuscript.

Funding: This research received no external funding.

Institutional Review Board Statement: Not applicable.

Informed Consent Statement: Informed consent was obtained from all subjects involved in the study.

Data Availability Statement: Not applicable.

Acknowledgments: This research study did not receive any specific support from individuals, public companies or commercial operations. Thanks to the anonymous reviewers for their comments and efforts to help improve the paper.

Conflicts of Interest: The authors declare no conflict of interest.

\section{References}

1. Van Deursen, A.J.; Bolle, C.L.; Hegner, S.M.; Kommers, P.A. Modeling habitual and addictive smartphone behavior: The role of smartphone usage types, emotional intelligence, social stress, self-regulation, age, and gender. Comput. Hum. Behav. 2015, 45, 411-420. [CrossRef]

2. Smith, A.; Page, D. US smartphone use in 2015. Pew Res. Center 2015. Available online: https://www.pewresearch.org/internet/ 2015/04/01/us-smartphone-use-in-2015/ (accessed on 28 March 2020).

3. Poushter, J. Smartphone ownership and internet usage continues to climb in emerging economies. Pew Res. Center 2016, 22, 1-44. Available online: https:/ / www.pewresearch.org/global/2016/02/22/smartphone-ownership-and-internet-usage-continuesto-climb-in-emerging-economies / (accessed on 2 April 2020).

4. Taylor, B.Y.K. ; Silver, L. Smartphone Ownership Is Growing Rapidly Around the World, but Not Always Equally. 2019. Available online: https:/ / www.pewresearch.org/global/2019/02/05/smartphone-ownership-is-growing-rapidly-around-the-worldbut-not-always-equally/ (accessed on 29 March 2020).

5. Li, S.; Da Xu, L.; Zhao, S. 5G Internet of Things: A survey. J. Ind. Inf. Integr. 2018, 10, 1-9. [CrossRef]

6. Al-Turjman, F. 5G-enabled devices and smart-spaces in social-IoT: An overview. Future Gener. Comput. Syst. 2019, 92, 732-744. [CrossRef]

7. Agiwal, M.; Saxena, N.; Roy, A. Towards connected living: 5g enabled internet of things (iot). IETE Tech. Rev. 2019, 36, 190-202. [CrossRef]

8. Malviya, S.; Saluja, D.; Singh, M.; Singh Thakur, A. A Study on the Factors Influencing Consumer's Purchase Decision Towards Smartphones in Indore. Int. J. Adv. Res. Comput. Sci. Manag. Stud. 2013, 1, 14-21.

9. Jain, S.; Singh, B. Consumer Behavior Toward Mobile Phone Handsets. In Proceedings of the International Conference on Innovative Computing and Communications, Singapore, 21-22 March 2019; Springer: Singapore, 2019; pp. 61-69.

10. Seva, R.R.; Duh, H.B.L.; Helander, M.G. The marketing implications of affective product design. Appl. Ergon. 2007, 38, 723-731. [CrossRef]

11. Yang, C.C. A classification-based Kansei engineering system for modeling consumers' affective responses and analyzing product form features. Expert Syst. Appl. 2011, 38, 11382-11393. [CrossRef]

12. Han, S.H.; Yun, M.H.; Kim, K.J. Evaluation of product usability: Development and validation of usability dimensions and design elements based on empirical models. Int. J. Ind. Ergon. 2000, 26, 477-488. [CrossRef]

13. Park, J.; Han, S.H. A fuzzy rule-based approach to modeling affective user satisfaction towards office chair design. Int. J. Ind. Ergon. 2004, 34, 31-47. [CrossRef]

14. Yadav, H.C.; Jain, R.; Shukla, S.; Avikal, S.; Mishra, P.K. Prioritization of aesthetic attributes of car profile. Int. J. Ind. Ergon. 2013, 43, 296-303. [CrossRef]

15. Han, S.H.; Yang, H. Screening important design variables for building a usability model: Genetic algorithm-based partial least-squares approach. Int. J. Ind. Ergon. 2004, 33, 159-171. [CrossRef]

16. Hou, W.; Jiang, Z.; Liao, X. A New Method of Smartphone Appearance Evaluation Based on Kansei Engineering. In Proceedings of the International Conference on Human-Computer Interaction, Orlando, FL, USA, 26-31 July 2019; Springer: Berlin/Heidelberg, Germany, 2019; pp. 439-449.

17. Hou, K.C.; Ho, C.H.; Lu, Y.N. Balance between Beauty and Usability in Kansei Interface for Smartphone. In Proceedings of the IASDR 2011 4th International Congress of International Association of Societies of Design Research, Delft, The Netherlands, 31 October-4 November 2011; pp. 1-6.

18. Li, S.; Chen, C.H. The effects of visual feedback designs on long wait time of mobile application user interface. Interact. Comput. 2019, 31, 1-12. [CrossRef] 
19. Nagamachi, M. Kansei engineering: A new ergonomic consumer-oriented technology for product development. Int. J. Ind. Ergon. 1995, 15, 3-11. [CrossRef]

20. Kruskal, J.B. Multidimensional scaling by optimizing goodness of fit to a nonmetric hypothesis. Psychometrika 1964, 29, 1-27. [CrossRef]

21. Huang, J. Multivariate Analysis, 7th ed.; Chinese Institute of Economics and Business, Taipei, Taiwan, 2000. (In Chinese)

22. Rohde, D.L. Methods for binary multidimensional scaling. Neural Comput. 2002, 14, 1195-1232. [CrossRef] [PubMed]

23. Borg, I.; Groenen, P.J.; Mair, P. Applied Multidimensional Scaling; Springer Science \& Business Media: Berlin/Heidelberg, Germany, 2012.

24. Kline, P. An Easy Guide to Factor Analysis; Routledge: London, UK, 2014.

25. Brown, F.G. Principles of Educational and Psychological Testing; Wadsworth Publishing Company: Belmont, CA, USA, 1983.

26. Zadeh, L.A. Fuzzy sets. Inf. Control 1965, 8, 338-353. [CrossRef]

27. Zadeh, L.A. Outline of a new approach to the analysis of complex systems and decision processes. IEEE Trans. Syst. Man Cybern. 1973, SMC-3, 28-44. [CrossRef]

28. Zadeh, L.A. The concept of a linguistic variable and its application to approximate reasoning-I. Inf. Sci. 1975, 8, 199-249. [CrossRef]

29. Hsiao, S.W. Fuzzy logic based decision model for product design. Int. J. Ind. Ergon. 1998, 21, 103-116. [CrossRef]

30. Lin, P.H.; Jin, Y.M. Applying fuzzy theory in selecting the image quality factors of 3D televisions. Int. J. Ind. Ergon. 2019, 74, 102841. [CrossRef]

31. Dubois, D.; Prade, H. Operations on fuzzy numbers. Int. J. Syst. Sci. 1978, 9, 613-626. [CrossRef]

32. Hsieh, C.H.; Chen, S.H. A model and algorithm of fuzzy product positioning. Inf. Sci. 1999, 121, 61-82. [CrossRef]

33. Chen, S.H. Ranking fuzzy numbers with maximizing set and minimizing set. Fuzzy Sets Syst. 1985, 17, 113-129. [CrossRef] 